\title{
Ketamine inhibits tumor necrosis factor secretion by RAW264.7 murine macrophages stimulated with antibiotic-exposed strains of community- associated, methicillin-resistant Staphylococcus aureus
}

Thomas Spentzas ${ }^{1,2,3^{*}}$, Rebekah KH Shapley ${ }^{1,2,3}$, Carlos Acuna Aguirre ${ }^{1,2,3}$, Elizabeth Meals ${ }^{1,2}$, Lauren Lazar ${ }^{1,2}$, Mark S Rayburn ${ }^{1,4}$, Brett S Walker ${ }^{1,2}$, B Keith English ${ }^{1,2,5}$

\begin{abstract}
Background: Infections caused by community-associated strains of methicillin-resistant Staphylococcus aureus (CAMRSA) are associated with a marked and prolonged host inflammatory response. In a sepsis simulation model, we tested whether the anesthetic ketamine inhibits the macrophage TNF response to antibiotic-exposed CA-MRSA bacteria via its antagonism of N-methyl-D-aspartate (NMDA) receptors. RAW264.7 cells were stimulated for 18 hrs with $10^{5}$ to $10^{7} \mathrm{CFU} / \mathrm{mL}$ inocula of either of two prototypical CA-MRSA isolates, USA300 strain LAC and USA400 strain MW2, in the presence of either vancomycin or daptomycin. One hour before bacterial stimulation, ketamine was added with or without MK-801 (dizocilpine, a chemically unrelated non-competitive NMDA receptor antagonist), APV (D-2-amino-5-phosphono-valerate, a competitive NMDA receptor antagonist), NMDA, or combinations of these agents. Supernatants were collected and assayed for TNF concentration by ELISA.

Results: RAW264.7 cells exposed to either LAC or MW2 in the presence of daptomycin secreted less TNF than in the presence of vancomycin. The addition of ketamine inhibited macrophage TNF secretion after stimulation with either of the CA-MRSA isolates (LAC, MW2) in the presence of either antibiotic. The NMDA inhibitors, MK-801 and APV, also suppressed macrophage TNF secretion after stimulation with either of the antibiotic-exposed CA-MRSA isolates, and the effect was not additive or synergistic with ketamine. The addition of NMDA substrate augmented TNF secretion in response to the CA-MRSA bacteria, and the addition of APV suppressed the effect of NMDA in a dose-dependent fashion.
\end{abstract}

Conclusions: Ketamine inhibits TNF secretion by MRSA-stimulated RAW264.7 macrophages and the mechanism likely involves NMDA receptor antagonism. These findings may have therapeutic significance in MRSA sepsis.

\section{Background}

Infections caused by community-associated strains of methicillin-resistant Staphylococcus aureus (CA-MRSA) present a major public health problem because of recent increases in the incidence of these infections [1,2]. In a 2007 report, the Centers for Disease Control concluded

\footnotetext{
* Correspondence: tom.spentzas@gmail.com

'Department of Pediatrics, University of Tennessee Health Science Center, Memphis, TN, USA

Full list of author information is available at the end of the article
}

that Staphylococcus aureus is now the most important cause of serious and fatal infection in the United States [3]. The prototypical USA400 strain, MW2, (CDC nomenclature for this strain of MRSA) was first isolated in 1999 from a Midwest child with fatal CA-MRSA pneumonia [4]. In 2003, the prototypical USA300 CAMRSA strain, LAC, was isolated from Los Angeles County patients with skin and soft tissue infections, severe pneumonia and sepsis. Recently, concerns about CA-MRSA infections were heightened after reports of

\section{Ciomed Central}


severe invasive staphylococcal infections in some patients infected with the novel $2009 \mathrm{H} 1 \mathrm{~N} 1$ influenza A virus $[5,6]$.

CA-MRSA isolates express many virulence factors $[7,8]$, including several cytolysins: $\alpha$-toxin, $\gamma$-toxin, Panton-Valentine leukocidin (PVL), phenol-soluble modulins (PSMs), $\delta$-toxin and, unlike traditional hospital-associated (HA-MRSA) isolates, may express superantigens such as TSST-1 [9]. These bacterial components can stimulate massive cytokine release and lead to septic shock, acute respiratory distress syndrome (ARDS) and death. It is likely that strategies designed to modulate the excessive and prolonged host inflammatory response could improve the outcome of fulminant MRSA infections.

Monocytes and macrophages play important roles in host defense against staphylococci and other pyogenic bacteria [10], but excessive systemic or local production of inflammatory mediators by macrophages could be deleterious in patients with severe staphylococcal infections. We previously reported that RAW264.7 murine macrophages exposed to any of a series of six pediatric clinical isolates of $S$. aureus (two CA-MRSA, two HAMRSA, and two methicillin-susceptible strains) in the presence of daptomycin (vs. vancomycin) secreted less TNF and accumulated less inducible nitric oxide synthase (iNOS) protein [11]. Vancomycin is a cell-wall active antibiotic that triggers bacterial lysis; it is the antibiotic most commonly used to treat severe MRSA infections in children [12]. Daptomycin is a novel antibiotic that is rapidly bactericidal against staphylococci but does not appear to cause rapid bacterial lysis; the mechanism of its action is not certain but it is reported to trigger depolarization of the bacterial membranes and inhibition of both DNA and RNA synthesis [13,14]. The rapid lysis of staphylococci, streptococci and other pyogenic bacteria exposed to cell-wall active antibiotics such as beta-lactams and vancomycin results in exaggerated release of bacterial products and an augmented and potentially harmful host inflammatory response $[15,16]$. Therefore, optimal treatment of sepsis and other severe bacterial infections might include the use of antibiotics and/or other medications that blunt the host inflammatory response and dampen the cytokine cascade [16].

Ketamine is one of the recommended anesthetics in pediatric septic shock [17-19], which is frequently caused by staphylococci $[12,20]$. The reasoning for ketamine's use in staphylococcal septic shock is its blood pressure supporting effect. It increases cardiac output and blood pressure, possibly via a catecholamine release mechanism $[17,21]$. Some data suggest that ketamine has anti-inflammatory effects [22-25]. For example, it has been reported that ketamine suppresses macrophage TNF secretion in response to Gram-negative bacterial
LPS in vivo and in vitro $[22,23,25]$. There is also one report that ketamine suppresses TNF production by human whole blood in vitro after exposure to staphylococcal enterotoxin B [24]. The mechanisms responsible for the anti-inflammatory effects of ketamine are not known [22-25].The present study examined the hypothesis that ketamine could suppress macrophage TNF production in response to whole bacteria, in this case clinical isolates of methicillin-resistant Staphylococcus aureus (MRSA). Given the important role of TNF in sepsis [26-29], and the importance of staphylococcal sepsis in children, such suppression could have a therapeutic impact.

Although membrane-bound Toll-like receptors (TLR2 and TLR4) are essential for lipopolysaccharide (LPS)induced TNF production [30], this is not the case for Staphylococcus aureus. Because S. aureus is able to "attack" or form pores in macrophages, TNF secretion occurs even in the absence of TLR 2 and TLR4 sensors (possibly via Nod1 and Nod2, intracytoplasmic sensors of peptidoglycan-derived muropeptides) [31]. Therefore, another mechanism independent of Toll-like receptors must exist for ketamine's anti-inflammatory action, at least in staphylococcal infections.

We also tested the effects of two chemically unrelated NMDA receptor antagonists, the anti-convulsant MK801 (dizocilpine) [32,33], a non-competitive inhibitor of NMDA receptors, and APV (D-2-amino-5-phosphonovalerate), a competitive NMDA receptor antagonist [34,35], as well as the NMDA substrate itself, on macrophage TNF secretion in response to antibiotic-treated CA-MRSA bacteria.

\section{Methods}

\section{Bacteria}

For these studies, we utilized two well-characterized clinical isolates: LAC (Los Angeles County), representative of the USA300 group of organisms and closely related to the dominant CA-MRSA clone associated with soft tissue infections and serious invasive disease in the Memphis area [1], and MW2, a clinical isolate from a midwestern child with fatal CA-MRSA sepsis [4], representative of the USA400 group of organisms that constitute the other main lineage of CA-MRSA isolates in the United States.

Bacteria were grown to late logarithmic phase at $37^{\circ} \mathrm{C}$ in tryptic soy broth (Becton Dickinson and Co., Sparks, MD) and washed three times in endotoxin-free phosphate-buffered saline. Concentrations were determined by colony counts. A range of concentrations of bacteria $\left(10^{5}-10^{7} \mathrm{CFU} / \mathrm{mL}\right)$ was studied, based upon our previously published data with other CA-MRSA strains [11] and our preliminary experiments using LAC and MW2 (data not shown). 
Minimum inhibitory concentrations (MICs) for these strains were determined by the microbiology laboratory at Le Bonheur Children's Hospital using the E-test method: both strains were fully susceptible to vancomycin and daptomycin (LAC: MIC vancomycin $1.0 \mu \mathrm{g} / \mathrm{mL}$; daptomycin $0.75 \mu \mathrm{g} / \mathrm{mL}$; MW2: MIC vancomycin < 0.5 $\mu \mathrm{g} / \mathrm{mL}$; daptomycin $0.75 \mu \mathrm{g} / \mathrm{mL}$ ).

\section{Cell culture}

RAW264.7 murine macrophage-like cells were purchased from the ATCC and cultured in Dulbecco's modified Eagle's medium (Mediatech Inc., Herndon, VA) supplemented with $10 \%$ fetal bovine serum (HyClone, Logan, UT) and $2 \mathrm{mM}$ glutamine (GIBCO, Carlsbad, CA). Experiments were done in 24-well tissue culture plates (Becton Dickinson, Lincoln Park, NJ) with $1 \times 10^{6}$ cells per well.

Either vancomycin or daptomycin was added to the cell cultures immediately before the addition of live staphylococci $\left(10^{5}-10^{7} \mathrm{CFU} / \mathrm{mL}\right)$. Cells were then incubated for 18 hours. Daptomycin was obtained from Cubist Pharmaceuticals (Lexington, MA). Vancomycin was purchased via the Department of Pharmacy at Le Bonheur Children's Hospital (LBCH) from Hospira (Lake Forest, IL). Clinically achievable concentrations of each of the antibiotics, as previously tested in our laboratory [11], were used $(20 \mu \mathrm{g} / \mathrm{mL})$.

These experiments were repeated in parallel in the presence of ketamine $(100 \mu \mathrm{M})$ and/or MK-801 (dizocilpine, $150 \mu \mathrm{M})$, APV (D-2-amino-5-phosphonovalerate, $300 \mu \mathrm{M}$ ("low") or $3 \mathrm{mM}$ ("high"), or NMDA $(30 \mu \mathrm{M})$. The modulation of MRSA-stimulated macrophage TNF production by ketamine was subsequently examined also at a range of concentrations of $10 \mu \mathrm{M}, 50 \mu \mathrm{M}, 100 \mu \mathrm{M}$ and $150 \mu \mathrm{M}$. The selected concentration $(100 \mu \mathrm{M})$ is based on the achievable anesthetic concentrations [36-39] and on the pre-existing literature related to ketamine's TNF suppressive effect on murine macrophage models when stimulated by LPS [23-25,27]. The concentrations for the other factors were selected from the available literature, MK-801 [40-42], APV and NMDA [32] have previously been studied in cell culture models and have been shown to not cause cytotoxicity at the tested concentrations. Ketamine and/or MK-801 or APV or NMDA were added to the macrophage cultures one hour prior to bacterial challenge. The source of ketamine was Ketalar ${ }^{\circledR}$, a racemic mixture (1:1) of optically active isomers ( $R$ and $L$ ) of this drug, purchased from the LBCH pharmacy. Emphasis in the experiment was placed on correlation with the clinical situation; thus racemic ketamine, the most commonly clinically used product, was selected. Dizocilpine (MK-801), APV and NMDA were purchased from Sigma Chemical Co. (St. Louis, MO).

After incubation, cell-free supernatants were collected and assayed for TNF concentrations by using a solid- phase sandwich enzyme-linked immunosorbent assay as specified by the manufacturer (eBioscience, San Diego, CA). TNF is a key cytokine produced by macrophages during MRSA stimulation. In our preliminary studies, we also measured secretion of other cytokines and found that IL-1, IL-6, and NO secretion were strongly correlated with TNF secretion in response to these bacteria $\left(r^{2}=0.84,0.87\right.$ and 0.93 , respectively). We focused on TNF secretion for these studies.

The tested concentrations of vancomycin, daptomycin, ketamine, MK-801, APV, and NMDA had no effect on the viability of the RAW264.7 cells, as determined by visual inspection of the monolayer, low power microscopic inspection of the monolayer and exclusion of $0.2 \%$ trypan blue dye.

For the single comparison experiments (ketamine or MK 801 or APV), TNF secretion measurements were validated with an average of at least three well replicates and each of the experiments was repeated at least three times (a total of at least nine samples). The four preliminary runs and all the exposures (total of 16) where the inocula were different from $10^{5}$ to $10^{7} \mathrm{CFUs} / \mathrm{mL}$ at the verifying colony count were excluded from the final analysis. Experiments with different exposure times $(6,10,14,24$ hours) were conducted to determine whether the inhibition increased over time. In the multiple comparison experiments (ketamine and MK 801 synergistic action), TNF was measured from at least four well replicates. All experiments were performed separately for LAC and for MW2 MRSA strains. There is an intrinsic experimental variation of absolute values of TNF production (up to $25 \%$ ) because of cell culture and macrophage growth characteristics.

\section{Data analysis}

The design was composed of factorial multiple measurements and the results were analyzed according to a mixed linear model, (GLIMMIX) SAS 9.2 (SAS Institute, Cary, NC) and R 2.9.1 and ggplot2 software. We set pre-planned (a priori) contrasts, i.e., we set all our comparisons in advance of multiple setting experiments. Significant differences were presumed at a probability value of $p<0.05$. The results were graphed using error bars with $95 \%$ confidence intervals. Differences in the means were estimated either with asymptotic techniques for normally distributed data or bootstrapping techniques for non-normally distributed data.

\section{Results}

CA-MRSA strains MW2 and LAC stimulated less TNF secretion by RAW264.7 murine macrophages in the presence of daptomycin than in the presence of vancomycin

As previously observed with two USA300 CA-MRSA strains isolated from Memphis children with invasive 
staphylococcal infections [11], macrophages exposed to either of the two prototypical CA-MRSA strains studied (the USA300 strain, LAC, or the USA400 strain, MW2) secreted significantly less TNF in the presence of daptomycin as compared with vancomycin (more than 50\% reduction in each strain; Figure 1). Macrophage TNF secretion in response to MW2 was 34,535 $\pm 1,536 \mathrm{pg} /$ $\mathrm{mL}$ in the presence of vancomycin and 15,377 $\pm 1,267$ $\mathrm{pg} / \mathrm{mL}$ in the presence of daptomycin, a reduction of $55 \%$, significant at $p<0.05$. Similarly, macrophage TNF secretion in response to LAC in the presence of vancomycin was $33,345 \pm 1,535 \mathrm{pg} / \mathrm{mL}$, and $14,432 \pm 1,536$ $\mathrm{pg} / \mathrm{mL}$ in the presence of daptomycin, a reduction of $57 \%$, significant at $p<0.05$. We previously reported similar findings in six $S$. aureus clinical isolates (including two pediatric CA-MRSA isolates of the USA300 group), suggesting that this effect of daptomycin is conserved in many different $S$. aureus isolates.

\section{Ketamine inhibited TNF secretion by murine macrophages stimulated with CA-MRSA isolates in the presence of antibiotics}

The addition of ketamine $(100 \mu \mathrm{M})$ to macrophage cell cultures inhibited TNF secretion in response to vancomycin- or daptomycin-exposed CA-MRSA isolates (Figure 2). The effect was similar on both strains, LAC

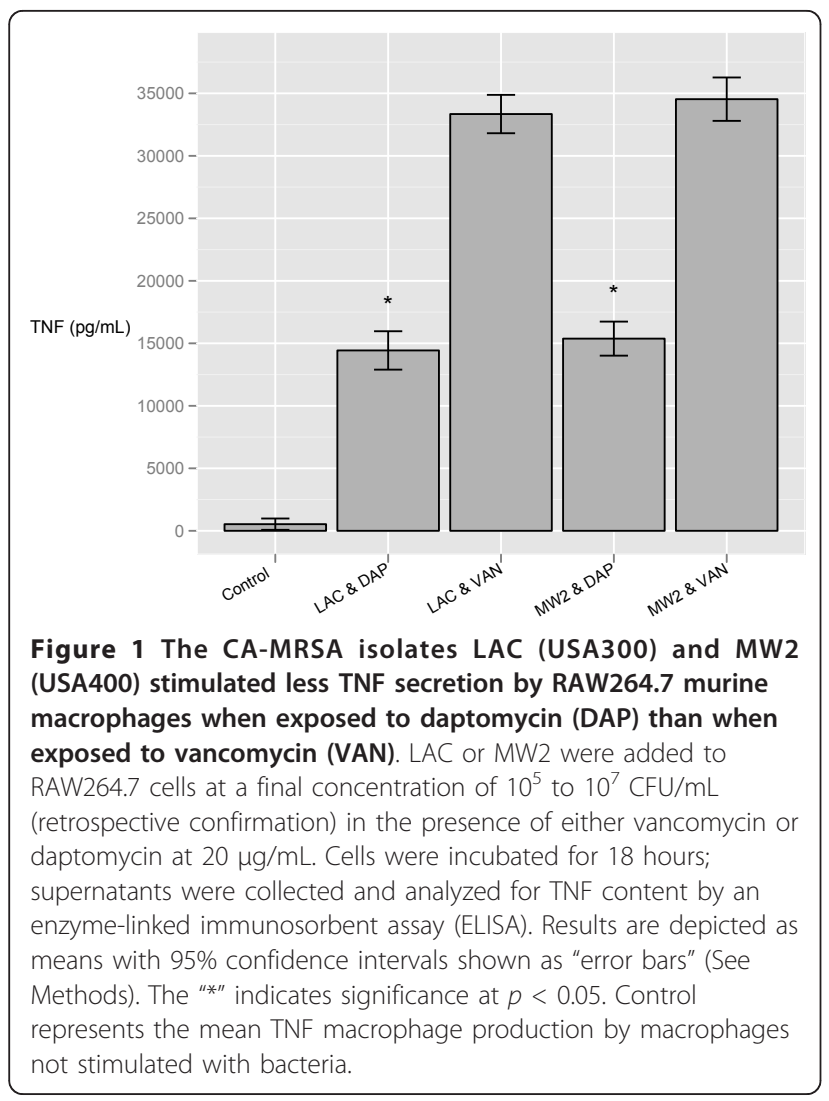

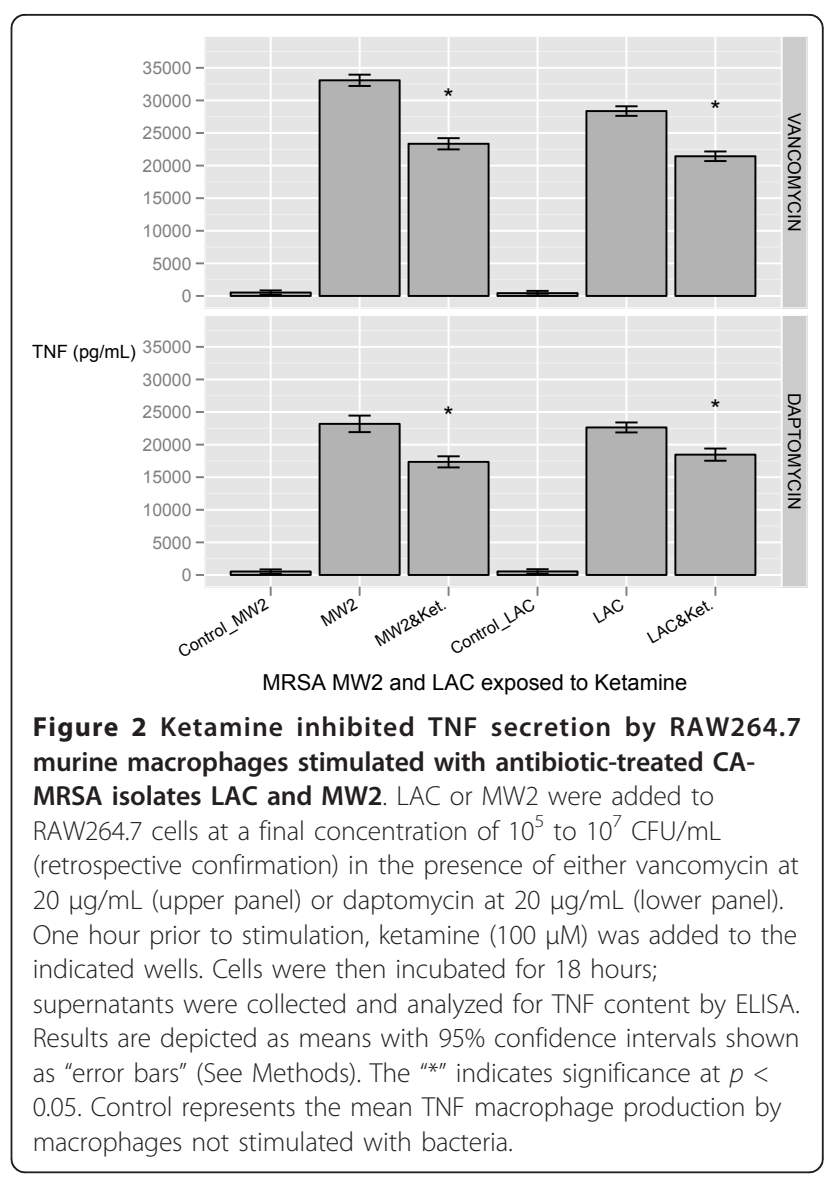

and MW2, in the presence of vancomycin (upper panel) or daptomycin (lower panel).

In the initial experiments we analyzed the effect of one hour pre-incubation with ketamine on the macrophage response to vancomycin-exposed CA-MRSA bacteria (MW2 and LAC). In response to vancomycinexposed MW2, pre-incubation with ketamine reduced macrophage TNF secretion by approximately $29 \%(p<$ $0.05)$, i.e., from $33,085 \pm 867 \mathrm{pg} / \mathrm{mL}$ to $23,347 \pm 862$ $\mathrm{pg} / \mathrm{mL}$. Pre-incubation with ketamine led to a similar reduction $(25 \% ; p<0.05)$ in macrophage TNF secretion response after stimulation with vancomycinexposed LAC (from $28,365 \pm 735 \mathrm{pg} / \mathrm{mL}$ to $21,432 \pm$ $736 \mathrm{pg} / \mathrm{mL})$.

We next studied the effect of ketamine pre-incubation on macrophage TNF secretion after stimulation with daptomycin-exposed MW2 or LAC. Once again, the addition of ketamine resulted in significant inhibition of macrophage TNF secretion in response to MW2 $(23,185 \pm 1,267 \mathrm{pg} / \mathrm{mL}$ to $17,354 \pm 853 \mathrm{pg} / \mathrm{mL}$, a reduction of approximately $25 \% ; p<0.05)$ or LAC (approximately $18 \%$ reduction, $p<0.05$; Figure 2 ). Adding ketamine after the MRSA inocula did not alter the response. 
The NMDA inhibitor MK-801 (dizocilpine) inhibited macrophage TNF secretion after stimulation with antibiotic-exposed CA-MRSA strains

Pre-incubation of RAW264.7 cells for one hour with the NMDA receptor antagonist, MK-801 (150 $\mu \mathrm{M})$, also inhibited TNF secretion by these cells after stimulation with antibiotic-exposed CA-MRSA strains (MW2 or LAC, Figure 3). In response to stimulation with MW2 in the presence of vancomycin, pre-incubation with MK-801 significantly inhibited TNF secretion by these cells, i.e., from $32,407 \pm 1,188 \mathrm{pg} / \mathrm{mL}$ to $23,337 \pm 1,272$ $\mathrm{pg} / \mathrm{mL}$ (approximately 28\% reduction; $p<0.05$, Figure 3, upper panel). MK-801 also inhibited macrophage TNF secretion in response to vancomycin-exposed LAC, causing a $34 \%$ reduction (Figure 3, upper panel).

Pre-incubation with MK-801 also significantly inhibited macrophage TNF secretion in response to daptomycin-treated MW2 or LAC (Figure 3, lower panel). In response to stimulation with $\mathrm{MW} 2$ in the presence of daptomycin, pre-incubation with MK-801 inhibited TNF secretion by these cells by approximately $26 \%$ (from $22,305 \pm 648 \mathrm{pg} / \mathrm{mL}$ to $16,437 \pm 642 \mathrm{pg} / \mathrm{mL}, p<0.05)$. MK-801 inhibited macrophage TNF secretion in response to daptomycin-exposed LAC by approximately

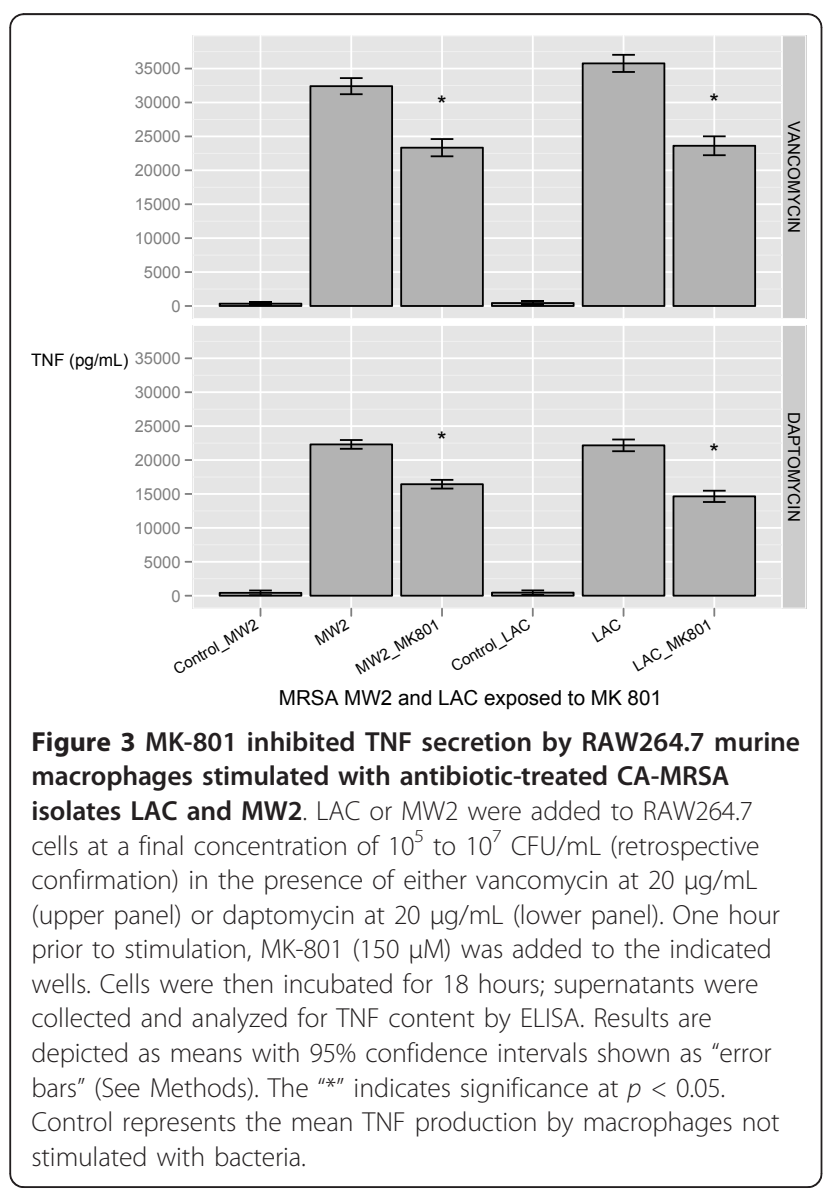

$33 \%$ (from $22,164 \pm 864 \mathrm{pg} / \mathrm{mL}$ to $14,647 \pm 832 \mathrm{pg} / \mathrm{mL}$, $p<0.05)$.

No additive or synergistic inhibition of macrophage TNF secretion is observed after pre-incubation with ketamine plus MK-801

Pre-incubation of RAW264.7 cells with combinations of MK-801 and ketamine did not affect the magnitude of inhibition of macrophage TNF secretion observed in the presence of ketamine (or MK-801) alone. Figure 4 depicts results for macrophages stimulated with vancomycin- or daptomycin-exposed MW2; responses to antibiotic-exposed LAC were similar (data not shown).

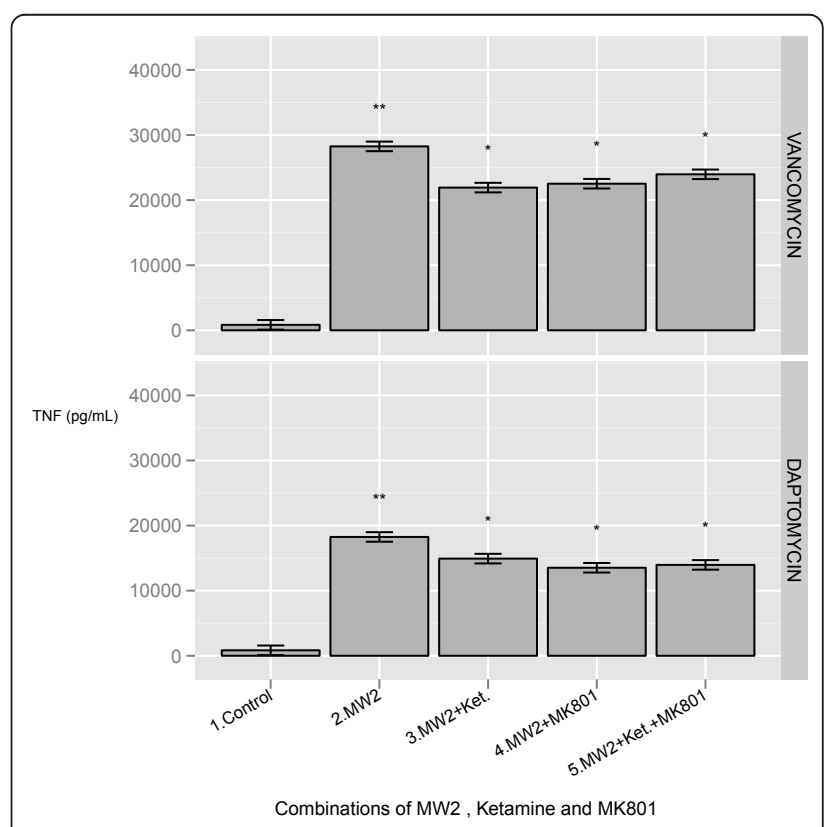

Figure 4 No additive or synergistic effects of combinations of MK-801 and ketamine on macrophage TNF secretion, in response to antibiotic-treated CA-MRSA strain MW2, were seen. Bacteria were added at a final concentration of $10^{5}$ to $10^{7} \mathrm{CFU} / \mathrm{mL}$ (retrospective confirmation) in the presence of either vancomycin at $20 \mu \mathrm{g} / \mathrm{mL}$ (upper panel) or daptomycin at $20 \mu \mathrm{g} / \mathrm{mL}$ (lower panel). One hour prior to stimulation, either ketamine at $100 \mu \mathrm{M}, \mathrm{MK}-801$ at $150 \mu \mathrm{M}$, or both were added to the indicated wells. Cells were then incubated for 18 hours; supernatants were collected and analyzed for TNF content by ELISA. Lane 1 (control) represents the mean TNF production by macrophages not stimulated with bacteria. The mean includes wells exposed to ketamine, MK-801, both ketamine and MK-801, and neither. In the absence of bacteria, TNF secretion was minimal and was not affected by ketamine and/or MK-801. Lanes 2 -5 depict mean TNF secretion by macrophages exposed to vancomycin-treated MW2 alone (lane 2), MW2 + ketamine (lane 3), MW2 + MK-801 (lane 4), or MW2 + ketamine + MK-801 (lane 5). The "*" on bars $3,4,5$ indicates that they are statistically different $(p<$ $0.05)$ from bars 1 and 2 . The "**" on bar 2 indicates significantly higher TNF production $(p<0.05)$. 


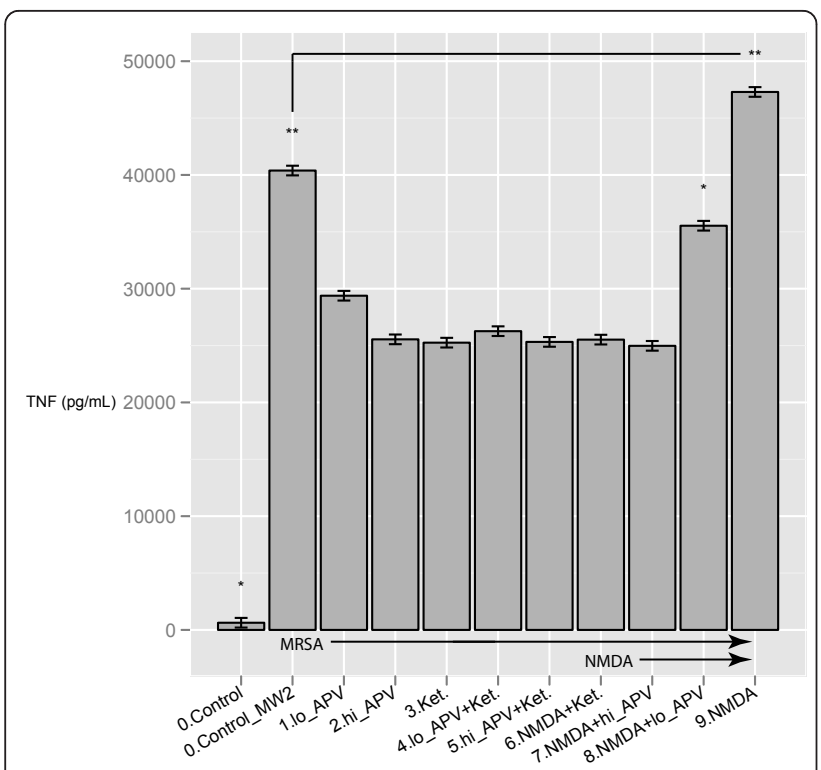

Figure 5 APV inhibited and NMDA augmented TNF secretion by RAW264.7 murine macrophages stimulated with the antibiotic-treated CA-MRSA isolate, MW2. Bacteria were added at a final concentration of $10^{5}$ to $10^{7} \mathrm{CFU} / \mathrm{mL}$ (retrospective confirmation) in the presence of vancomycin at $20 \mu \mathrm{g} / \mathrm{mL}$. One hour prior to stimulation, APV ("low" concentration of $300 \mu \mathrm{M}$ or "high" concentration of $3 \mathrm{mM}$ ), ketamine $(100 \mu \mathrm{M})$, or NMDA (30 $\mu \mathrm{M})$ were added, alone or in combination, as indicated. Cells were then incubated for 18 hours; supernatants were collected and analyzed for TNF content by ELISA. The control lane represents the mean TNF macrophage production by macrophages not stimulated with bacteria. The mean includes wells exposed to APV, ketamine, or NMDA alone or in combination. In the absence of bacteria, TNF secretion was minimal and was not affected by APV, ketamine, or NMDA. Lanes 0-9 depict mean TNF secretion by macrophages exposed to vancomycin-treated MW2 alone (lane 0) or in the presence of the indicated concentrations of APV, ketamine, and/or NMDA (lanes 1-9). TNF secretion was reduced by approximately 30$40 \%$ when macrophages were pre-incubated with APV, ketamine, or APV + ketamine (lanes 1-5). The magnitude of inhibition by ketamine and high-dose APV was similar and there were no additive or synergistic effect observed with combinations of ketamine and APV. Addition of NMDA $(30 \mu \mathrm{M})$ led to a substantial increase in the amount of TNF secreted in response to the MW2 strain (lane 9), and this augmented response was blocked by both APV and ketamine. The "**" on "0.Control" and "8.NMDA+lo_APV" bars indicates significance at $p<0.05$. The "**" on "0.Control_MW2" and "9.NMDA" bars indicates differences between the pretreated wells, and that TNF production after MRSA stimulation with NMDA substrate (9.NMDA) is significantly higher than that at the baseline MRSA stimulation (0.Control_MW2) at $p<0.05$.

NMDA augments macrophage TNF secretion in response to antibiotic-treated CA-MRSA bacteria: both ketamine and a competitive NMDA receptor antagonist, APV, block this effect

We further examined the role of NMDA receptors in modulating the macrophage TNF response to the CAMRSA bacteria by studying the effects of a competitive
NMDA receptor antagonist, APV, and the effects of the NMDA substrate itself (Figure 5). We found that APV (at either $300 \mu \mathrm{M}$ or $3 \mathrm{mM}$ ) also inhibited macrophage TNF secretion in response to vancomycin-exposed MW2 $(p<0.05$, Figure 5). The magnitude of the inhibition was comparable to that observed with either ketamine or MK-801 (and, as in the case of MK-801, was not additive or synergistic with ketamine). Furthermore, the addition of the NMDA substrate $(30 \mu \mathrm{M})$ resulted in a marked augmentation of the macrophage TNF response to the antibiotic-treated CA-MRSA bacteria $(p<0.05)$, and this effect was blocked by ketamine and by the competitive NMDA receptor antagonist, APV (Figure 5).

\section{Inhibition of macrophage TNF secretion is observed across a range of ketamine concentrations and throughout the incubation period}

We next studied the effects of a range of concentrations of ketamine and found that inhibition of macrophage TNF secretion in response to vancomycinexposed LAC or MW2 was consistently observed at concentrations of ketamine at the lowest concentration tested $(10 \mu \mathrm{M})$ and was greater at concentrations of 50 $-150 \mu \mathrm{M}$ (Figure 6).

We also examined the kinetics of inhibition of macrophage TNF secretion by incubating RAW264.7 cells for $6,10,14,18$ and 24 hours after exposure to ketamine at a concentration of $100 \mu \mathrm{M} 1$ hour prior to stimulation with vancomycin-exposed LAC or MW2. We found that the magnitude of suppression of TNF secretion was similar at all times studied (Figure 7).

\section{Discussion}

We found that exposure of murine macrophages to ketamine inhibited TNF secretion by $18-34 \%$ after stimulation with CA-MRSA bacteria in the presence of antibiotics. The magnitude of the effect was comparable in response to both MW2 (USA400) and LAC (USA300) bacteria and was similar in the presence of either vancomycin (a lytic antibiotic associated with a greater TNF response to the bacteria) or daptomycin (a non-lytic antibiotic associated with a blunted TNF response to the bacteria). Our data suggest that ketamine administration to macrophages stimulated by CAMRSA is associated with blunting of the TNF response to these virulent pathogens, and suggest that these findings may have therapeutic significance in MRSA sepsis. Furthermore, these data confirm and extend our previous observations that CA-MRSA bacteria exposed to daptomycin (versus vancomycin) trigger less TNF secretion by macrophages. The potentially beneficial antiinflammatory effects of daptomycin and ketamine were additive (Figures 2, 3). 


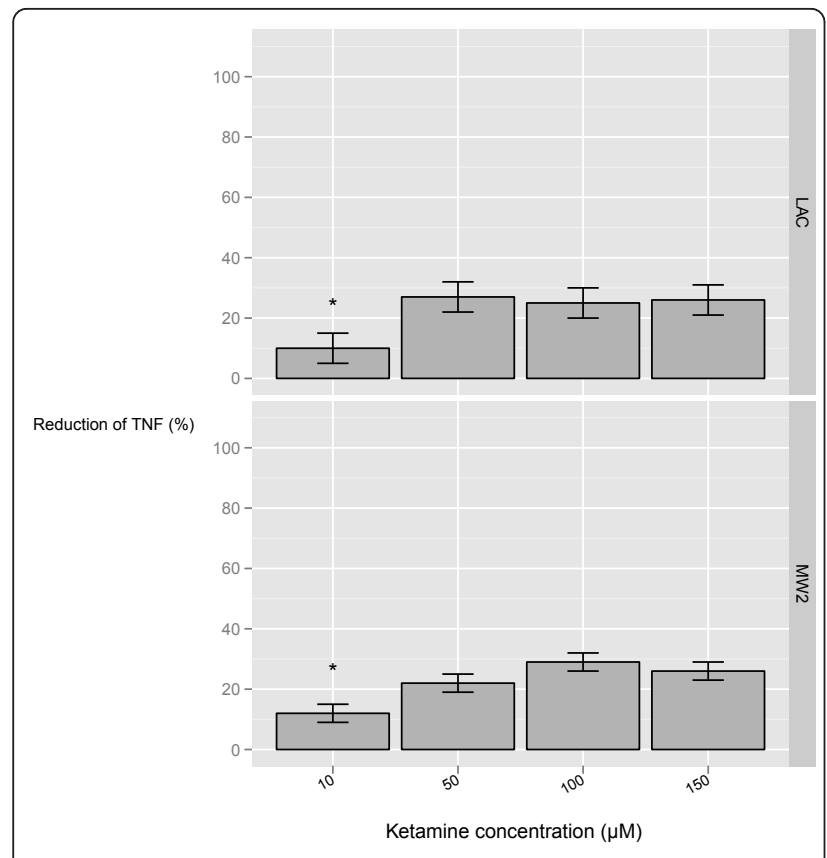

Figure 6 TNF suppression by ketamine was tested at concentrations of $10 \mu \mathrm{M}, 50 \mu \mathrm{M}, 100 \mu \mathrm{M}$ and $150 \mu \mathrm{M}$ in the presence of vancomycin at $20 \mu \mathrm{g} / \mathrm{mL}$ and RAW264 macrophage stimulation with either LAC (upper panel) or MW2 (lower panel) CA-MRSA strains. Bacteria were added at a final concentration of $10^{5}$ to $10^{7} \mathrm{CFU} / \mathrm{mL}$ (retrospective confirmation) in the presence of vancomycin at $20 \mathrm{\mu g} / \mathrm{mL}$. The inoculation time was 18 hours. Results are depicted as percentile reduction with 95\% confidence intervals shown, i.e., the percent of TNF reduction that occurs after the specific concentration of ketamine was added.

An improved understanding of the pathogenesis of sepsis and other life-threatening infections caused by CAMRSA bacteria could expedite the development of novel strategies for the diagnosis, treatment, and/or prevention of these serious infections. CA-MRSA infections often are associated with severe and prolonged host inflammatory responses [43-46]. Prompt antibiotic treatment of these and other serious bacterial infections is indicated, but paradoxically has the potential to trigger excessive release of bacterial products and the subsequent augmentation of the host inflammatory response $[15,16]$. Macrophages are important sources of many of the proinflammatory cytokines (including IL-1 $\beta$, IL-6, IL-8, IL-12, and TNF) secreted in response to staphylococci and other Gram-positive bacteria [15,16,41]. Although the cytokine cascade is essential for normal host defense, excessive or inappropriate inflammation can be harmful. Therefore we need an improved understanding of these interactions in order to develop better adjunctive therapies for patients with severe bacterial infections.

In a previous study, we found that exposure of either of two CA-MRSA strains isolated from Memphis children (or any of four other S. aureus isolates from

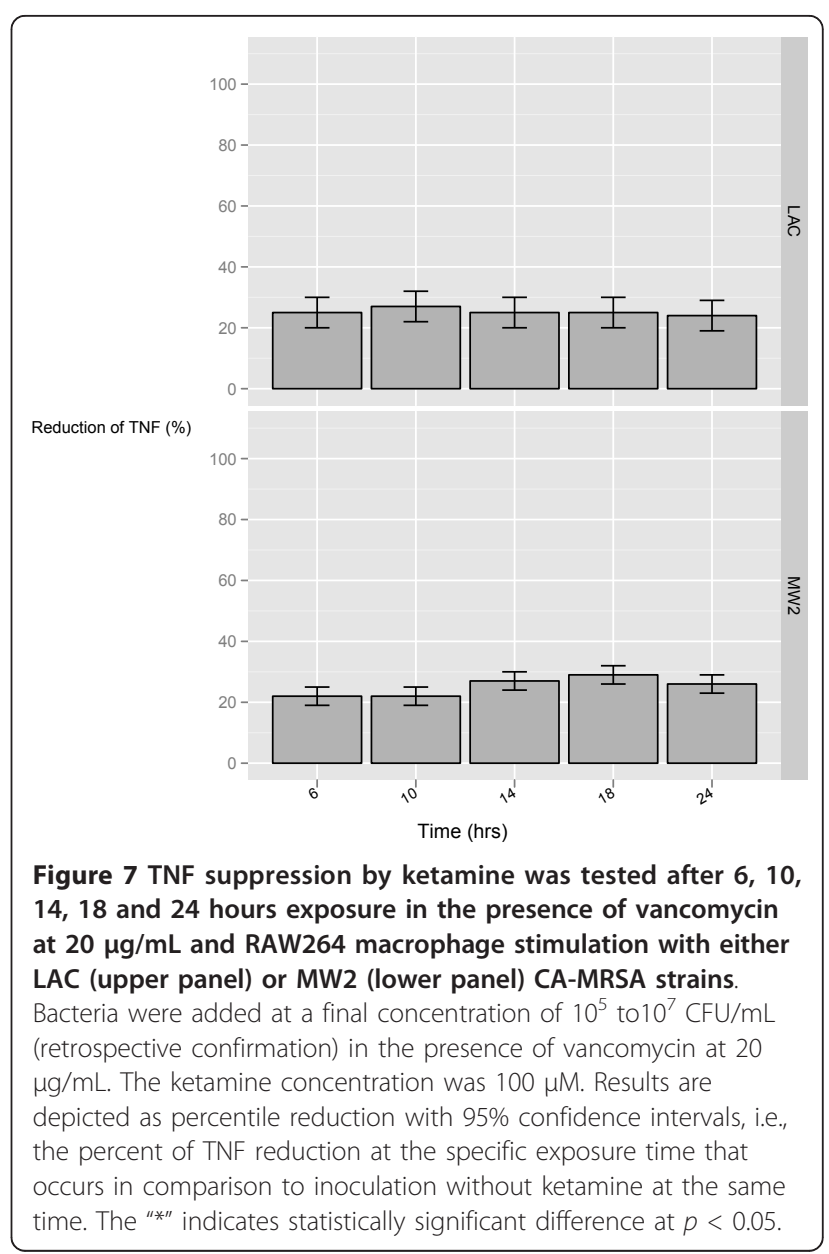

children with invasive staphylococcal infections) to daptomycin (compared with vancomycin) led to a less pronounced macrophage inflammatory response, characterized by diminished secretion of TNF and reduced accumulation of the inducible nitric oxide synthase (iNOS) [11]. In this study, we found that this differential effect of daptomycin (versus vancomycin) was also observed when macrophages were stimulated with either of the two prototypical CA-MRSA strains most widely studied today: the USA400 isolate, MW2, and the USA300 isolate, LAC. Importantly, ketamine pre-incubation inhibited macrophage TNF secretion in response to both CA-MRSA strains in the presence of daptomycin as well as in the presence of vancomycin, and the greatest suppression of TNF secretion was noted in the presence of both daptomycin and ketamine.

The mechanism(s) responsible for the anti-inflammatory properties of ketamine are not known, but its neurological and psychotropic actions are believed primarily to be mediated by antagonism of NMDA receptors $[21,47]$. Glutamate is the brain's primary excitatory neurotransmitter. NMDA receptors are found in many cell 
types, including blood lymphocytes, lung macrophages, and multiple hematopoietic precursors in bone marrow cells $[40,42,47,48]$. Both ketamine and the chemically unrelated anticonvulsant dizocilpine (MK-801) are noncompetitive antagonists of the NMDA receptor, one of the three known glutamate receptors [32,33,47]. APV is a competitive inhibitor of the classical NMDA receptor and acts on the NR2 component of the receptor $(30,33)$.

We found that MK-801 and APV also inhibited macrophage TNF secretion in response to antibiotictreated MW2 or LAC cells. The magnitude of the inhibition by MK-801 (approximately 30\%) and APV (25-35\%) was comparable to that observed with ketamine (18-34\%), and combinations of MK-801 and ketamine or of APV and ketamine did not exhibit additive or synergistic inhibition of TNF secretion. Furthermore, adding NMDA led to augmented macrophage TNF secretion in response to antibiotic-treated CA-MRSA bacteria, and the NMDA receptor antagonist, APV, blocked this effect. The suppression of TNF induced by ketamine was observed across a range of concentrations and throughout the incubation period.

Our study has its limitations. To translate the present findings, we are currently working on a clinical model to assess the clinical significance of ketamine's anti-inflammatory effects in patients with bacterial sepsis. Although studies of the effect of ketamine on macrophage responses to purified bacterial components such as Gram-negative lipopolysaccharide (LPS) or Gram-positive lipoteichoic acid (LTA) are instructive $[23,24,49]$, we argue that characterization of the macrophage responses to whole organisms is more likely to provide clinical insights. Indeed, the pioneering experiments of Carswell and Old that identified TNF used whole bacteria as stimuli in macrophage sepsis simulation settings [49], and we have previously demonstrated that macrophage responses to live, antibiotic-treated staphylococci serve as a powerful model system. Furthermore, the model examines the effect of ketamine only in the presence of antibiotics (either vancomycin or daptomycin). In practice, this is a common clinical scenario. Our data suggest that clinically achievable concentrations of both ketamine and daptomycin could potentially inhibit the excessive macrophage inflammatory response that is observed in patients with severe staphylococcal infections.

\section{Conclusions}

In the battle of sepsis everything counts. Adjunctive therapies of sepsis are greatly needed. Studies in animal models and clinical trials will be required to determine whether the anti-inflammatory effects of ketamine and/or other agents that block NMDA receptors could be beneficial in the treatment of severe staphylococcal infections.

\section{Presented in part at}

National Society of Critical Care meeting in Nashville, TN, Feb. 2009

Southern Society of Clinical Investigation/American Federation for Medical Research meeting in New Orleans, LA, Feb. 2009

Pediatric Academic Societies' research meeting in Baltimore, MD, May 2009

American Academy of Pediatrics Section of Critical Care, Washington DC, October 2009

\section{Abbreviations}

CA-MRSA: community-associated methicillin-resistant Staphylococcus aureus; NMDA: N-methyl-D-aspartate; HA-MRSA: hospital-associated methicillinresistant Staphylococcus aureus; iNOS: nitric oxide synthase; LPS: lipopolysaccharide; LTA: lipoteichoic acid; PVL: Panton-Valentine leukocidin; PSM: phenol-soluble modulins; APV: D-2-amino-5-phosphono-valerate; MK801: dizocilpine; CFU: colony forming units; IL 1-12: interleukin 1-12; Le Bonheur Children's Hospital (LBCH)

\section{Acknowledgements}

The study was sponsored by the Methodist Foundation Le Bonheur Small Grants and the Bea Gerber Award. Other research being performed in Dr. English's laboratory is supported by Cubist Pharmaceuticals (the makers of daptomycin), but Cubist did not fund this project. The authors would like to thank Andrea Patters for her editorial assistance, Thomas T. Spentzas for his help with the graphics and Dr Sunny Anand for reviewing the manuscript.

\section{Author details}

'Department of Pediatrics, University of Tennessee Health Science Center, Memphis, TN, USA. ${ }^{2}$ Children's Foundation Research Center at Le Bonheur Children's Hospital, Memphis, TN, USA. ${ }^{3}$ Division of Pediatric Critical Care Medicine, Le Bonheur Children's Hospital, Memphis, TN, USA. ${ }^{4}$ Department of Clinical Pharmacy, Le Bonheur Children's Hospital, Memphis, TN, USA. ${ }^{5}$ Division of Pediatric Infectious Diseases, Le Bonheur Children's Hospital, Memphis, TN, USA.

\section{Authors' contributions}

TS, RKHS, CAA, EM, LL and BSW contributed to acquisition of data. MSR was the medication consultant. TS, EM and BKE contributed to the conception and design and interpretation of the data. TS contributed to the statistical analysis. TS, EM and BKE gave the final approval.

\section{Competing interests}

The authors declare that they have no competing interests.

Received: 22 September 2010 Accepted: 25 January 2011

Published: 25 January 2011

\section{References}

1. Buckingham SC, McDougal LK, Cathey LD, Comeaux K, Craig AS, Fridkin SK, Tenover FC: Emergence of community-associated methicillin-resistant Staphylococcus aureus at a Memphis, Tennessee children's hospital. Pediatr Infect Dis J 2004, 23:619-24.

2. Moran GJ, Krishnadasan A, Gorwitz RJ, Fosheim GE, McDougal LK, Carey RB, Talan DA: Methicillin-resistant $S$. aureus infections among patients in the emergency department. N Engl J Med 2006, 355:666-74.

3. Klevens RM, Morrison MA, Nadle J, Petit S, Gershman K, Ray S, Harrison LH, Lynfield R, Dumyati G, Townes JM, Craig AS, Zell ER, Fosheim GE, McDougal LK, Carey RB, Fridkin SK: Invasive methicillin-resistant Staphylococcus aureus infections in the United States. Jama 2007, 298:1763-71.

4. Centers for Disease Control and Prevention: Four pediatric deaths from community-acquired methicillin-resistant Staphylococcus aureusMinnesota and North Dakota, 1997-1999. MMWR 1999, 48:707-710.

5. Hidron Al, Low CE, Honig EG, Blumberg HM: Emergence of communityacquired methicillin-resistant Staphylococcus aureus strain USA300 as a 
cause of necrotising community-onset pneumonia. Lancet Infect Dis 2009, 9:384-92.

6. Reed C, Kallen AJ, Patton M, Arnold KE, Farley MM, Hageman J, Finelli L: Infection with community-onset Staphylococcus aureus and influenza virus in hospitalized children. Pediatr Infect Dis J 2009, 28:572-6.

7. Nygaard TK, DeLeo FR, Voyich JM: Community-associated methicillinresistant Staphylococcus aureus skin infections: advances toward identifying the key virulence factors. Curr Opin Infect Dis 2008, 21:147-52

8. Nygaard TK, Pallister KB, Ruzevich P, Griffith S, Vuong C, Voyich JM: SaeR binds a consensus sequence within virulence gene promoters to advance USA300 pathogenesis. J Infect Dis 2010, 201:241-54.

9. Assimacopoulos AP, Strandberg KL, Rotschafer JH, Schlievert PM: Extreme pyrexia and rapid death due to Staphylococcus aureus infection: analysis of 2 cases. Clin Infect Dis 2009, 48:612-4

10. Cavaillon JM, Adib-Conquy M: Monocytes/macrophages and sepsis. Crit Care Med 2005, 33:S506-9.

11. English BK, Maryniw EM, Talati AJ, Meals EA: Diminished macrophage inflammatory response to Staphylococcus aureus isolates exposed to daptomycin versus vancomycin or oxacillin. Antimicrob Agents Chemother 2006, 50:2225-7.

12. Creel AM, Durham SH, Benner KW, Alten JA, Winkler MK: Severe invasive community-associated methicillin-resistant Staphylococcus aureus infections in previously healthy children. Pediatr Crit Care Med 2009, 10:323-7.

13. Mascio CT, Alder JD, Silverman JA: Bactericidal action of daptomycin against stationary-phase and nondividing Staphylococcus aureus cells. Antimicrob Agents Chemother 2007, 51:4255-60.

14. Micklefield J: Daptomycin structure and mechanism of action revealed. Chem Biol 2004, 11:887-8.

15. Mogensen $\mathrm{TH}$ : Pathogen recognition and inflammatory signaling in innate immune defenses. Clin Microbiol Rev 2009, 22:240-73.

16. Nau R, Eiffert $\mathrm{H}$ : Modulation of release of proinflammatory bacterial compounds by antibacterials: potential impact on course of inflammation and outcome in sepsis and meningitis. Clin Microbiol Rev 2002, 15:95-110

17. Carcillo JA, Cunnion RE: Septic shock. Crit Care Clin 1997, 13:553-74.

18. Carcillo JA, Davis AL, Zaritsky A: Role of early fluid resuscitation in pediatric septic shock. Jama 1991, 266:1242-5.

19. Carcillo JA, Fields Al: Clinical practice parameters for hemodynamic support of pediatric and neonatal patients in septic shock. Crit Care Med 2002, 30:1365-78.

20. Watson RS, Carcillo JA: Scope and epidemiology of pediatric sepsis. Pediatr Crit Care Med 2005, 6:S3-5.

21. Chang $Y$, Chen $T L$, Sheu JR, Chen RM: Suppressive effects of ketamine on macrophage functions. Toxicol Appl Pharmacol 2005, 204:27-35.

22. Eyjolfsson EM, Brenner E, Kondziella D, Sonnewald U: Repeated injection of MK801: an animal model of schizophrenia? Neurochem Int 2006, 48:541-6.

23. Kawasaki C, Kawasaki T, Ogata M, Nandate K, Shigematsu A: Ketamine isomers suppress superantigen-induced proinflammatory cytokine production in human whole blood. Can J Anaesth 2001, 48:819-23.

24. Kawasaki T, Ogata M, Kawasaki C, Ogata J, Inoue Y, Shigematsu A: Ketamine suppresses proinflammatory cytokine production in human whole blood in vitro. Anesth Analg 1999, 89:665-9.

25. Koga K, Ogata M, Takenaka I, Matsumoto T, Shigematsu A: Ketamine suppresses tumor necrosis factor-alpha activity and mortality in carrageenan-sensitized endotoxin shock model. Circ Shock 1994, 44:160-8.

26. Beutler B, Cerami A: Tumor necrosis, cachexia, shock, and inflammation: a common mediator. Annu Rev Biochem 1988, 57:505-18.

27. Cohen J, Abraham E: Microbiologic findings and correlations with serum tumor necrosis factor-alpha in patients with severe sepsis and septic shock. J Infect Dis 1999, 180:116-21.

28. Esposito E, Cuzzocrea S: TNF-alpha as a therapeutic target in inflammatory diseases, ischemia-reperfusion injury and trauma. Curr Med Chem 2009, 16:3152-67.

29. Grewal IS: Overview of TNF superfamily: a chest full of potential therapeutic targets. Adv Exp Med Biol 2009, 647:1-7.

30. Lien E, Sellati TJ, Yoshimura A, Flo TH, Rawadi G, Finberg RW, Carroll JD, Espevik T, Ingalls RR, Radolf JD, Golenbock DT: Toll-like receptor 2 functions as a pattern recognition receptor for diverse bacterial products. J Biol Chem 1999, 274:33419-25.
31. Kapetanovic R, Nahori MA, Balloy V, Fitting C, Philpott DJ, Cavaillon JM, Adib-Conquy M: Contribution of phagocytosis and intracellular sensing for cytokine production by Staphylococcus aureus-activated macrophages. Infect Immun 2007, 75:830-7.

32. Morris RG: Synaptic plasticity and learning: selective impairment of learning rats and blockade of long-term potentiation in vivo by the $\mathrm{N}$ methyl-D-aspartate receptor antagonist AP5. J Neurosci 1989, 9:3040-57.

33. Olney JW, Labruyere J, Price MT: Pathological changes induced in cerebrocortical neurons by phencyclidine and related drugs. Science 1989, 244:1360-2.

34. Kudoh M, Sakai M, Shibuki K: Differential dependence of LTD on glutamate receptors in the auditory cortical synapses of cortical and thalamic inputs. J Neurophysiol 2002, 88:3167-74.

35. van Dissel JT, van Langevelde $P$, Westendorp RG, Kwappenberg K Frolich M: Anti-inflammatory cytokine profile and mortality in febrile patients. Lancet 1998, 351:950-3.

36. VF Feng N, Minder El, Rentsch K, Grampp T, Vonderschmitt DJ: Development of a gas chromatography-mass spectrometry method for determination of ketamine in plasma and its application to human samples. Ther. Drug Monit 1995, 17:95-100.

37. Idvall J, Ahlgren I, Aronsen KR, Stenberg P: Ketamine infusions: pharmacokinetics and clinical effects. Br J Anaesth 1979, 51:1167-73.

38. TS Parkin MC, Smith NW, Halket JM, Braithwaite RA, Elliott SP, Osselton MD, Cowan DA, Kicman AT: Detection of ketamine and its metabolites in urine by ultra high pressure liquid chromatography-tandem mass spectrometry. J. Chrom 2008, B876:137-142.

39. Wieber J, Gugler R, Hengstmann JH, Dengler HJ: Pharmacokinetics of ketamine in man. Anaesthesist 1975, 24:260-3.

40. Genever PG, Wilkinson DJ, Patton AJ, Peet NM, Hong Y, Mathur A Erusalimsky JD, Skerry TM: Expression of a functional N-methyl-Daspartate-type glutamate receptor by bone marrow megakaryocytes. Blood 1999, 93:2876-83.

41. Mukhin AG, Ivanova SA, Knoblach SM, Faden Al: New in vitro model of traumatic neuronal injury: evaluation of secondary injury and glutamate receptor-mediated neurotoxicity. J Neurotrauma 1997, 14:651-63.

42. Pearce IA, Cambray-Deakin MA, Burgoyne RD: Glutamate acting on NMDA receptors stimulates neurite outgrowth from cerebellar granule cells. FEBS Lett 1987, 223:143-7.

43. Bubeck Wardenburg J, Palazzolo-Ballance AM, Otto M, Schneewind O, DeLeo FR: Panton-Valentine leukocidin is not a virulence determinant in murine models of community-associated methicillin-resistant Staphylococcus aureus disease. J Infect Dis 2008, 198:1166-70.

44. Fast DJ, Schlievert PM, Nelson RD: Toxic shock syndrome-associated staphylococcal and streptococcal pyrogenic toxins are potent inducers of tumor necrosis factor production. Infect Immun 1989, 57:291-4.

45. Gillet $Y$, Issartel B, Vanhems P, Fournet JC, Lina G, Bes M, Vandenesch F, Piemont $Y$, Brousse N, Floret D, Etienne J: Association between Staphylococcus aureus strains carrying gene for Panton-Valentine leukocidin and highly lethal necrotising pneumonia in young immunocompetent patients. Lancet 2002, 359:753-9.

46. Voyich JM, Otto M, Mathema B, Braughton KR, Whitney AR, Welty D, Long RD, Dorward DW, Gardner DJ, Lina G, Kreiswirth BN, DeLeo FR: Is Panton-Valentine leukocidin the major virulence determinant in community-associated methicillin-resistant Staphylococcus aureus disease? J Infect Dis 2006, 194:1761-70.

47. Lombardi G, Miglio G, Dianzani C, Mesturini R, Varsaldi F, Chiocchetti A, Dianzani U, Fantozzi R: Glutamate modulation of human lymphocyte growth: in vitro studies. Biochem Biophys Res Commun 2004, 318:496-502.

48. Gill R, Foster AC, Woodruff GN: Systemic administration of MK-801 protects against ischemia-induced hippocampal neurodegeneration in the gerbil. J Neurosci 1987, 7:3343-9.

49. Carswell EA, Old LJ, Kassel RL, Green S, Fiore N, Williamson B: An endotoxin-induced serum factor that causes necrosis of tumors. Proc Natl Acad Sci USA 1975, 72:3666-70.

doi:10.1186/1471-2172-12-11

Cite this article as: Spentzas et al:: Ketamine inhibits tumor necrosis factor secretion by RAW264.7 murine macrophages stimulated with antibiotic-exposed strains of community-associated, methicillin-resistant Staphylococcus aureus. BMC Immunology 2011 12:11. 